the NICE bronchiolitis guidelines (NG9) which now recommends isotonic fluids.

Aim To investigate patterns of IV fluid administration and analyse plasma sodium measurements in children with bronchiolitis admitted to a busy paediatric unit.

Methods Audit of all infants with bronchiolitis, on IV fluids between November 2016 and January 2017. The audit protocol was derived from NICE guidance (NG9).

Results Thirty- two out of 237 patients admitted with bronchiolitis received IV fluids (13.5\%). Data was available for twenty- nine infants. The median age was 7 weeks and the majority were male $(n=20)$. The most common pathogen isolated was RSV in $85.7 \%$ of cases.

Seventeen (58.6\%) infants received isotonic fluids however, 16 $(55.2 \%)$ received hypotonic or a mixture of hypotonic and isotonic solutions. Two infants were hyponatraemic on admission (sodium $121 \mathrm{mmol} / \mathrm{L}$ and $129 \mathrm{mmol} / \mathrm{L}$ respectively), however none developed iatrogenic hyponatraemia. There was a single case of hypernatraemia in the isotonic fluids group (sodium $147 \mathrm{mmol} / \mathrm{L}$ ). There was no significant difference in change in sodium between those receiving purely hypotonic or isotonic solutions. Moreover, there was no association observed between rate of IV infusion (boluses not included) and change in sodium however, there was a significant association with duration of intravenous fluids $(p=0.012)$. Two infants had large variations in plasma sodium of 10 and $12 \mathrm{mmol} / \mathrm{L}$ respectively.

Conclusions Significant changes in plasma sodium can occur whilst children are receiving IV fluids. This highlights the importance of regular electrolyte monitoring and regular assessment of the need for on-going fluid administration.

\section{G139(P) AWARDS FOR EXCELLENCE IN PAEDIATRICS: A TRAINEES' PERSPECTIVE IN IMPROVING MORALE}

L Rowley, I Misra, J Srinivas. Paediatrics, Milton Keynes University Hospital, Milton Keynes, UK

10.1136/archdischild-2018-rcpch. 135

Background and aims The paediatric team at Milton Keynes University Hospital has a monthly Award for Excellence, where all staff could nominate any other member of staff for excellence at work. We hoped that this would improve team morale by giving opportunity to celebrate the nominated staff and to make staff feel more appreciated.

We analysed the awards over last 12 months to review junior doctors' role in nominating and receiving nominations.

Method Review of nominations for the last 12 months. Designation of staff who filled the nominations and those that were nominated was collected along the reasons for nomination.

Results 54 members of staff were nominated for the Excellence award in the last 12 months. Most of the nominations were by consultants (42\%) and nurses (33\%). Wide ranges of professionals were recommended for these awards but the most common were nurses (44\%) and junior doctors (26\%).

The reasons for nominations were varied and included good communication, hard work, great leadership, compassion and feedback from patients. Informal feedback from few of the award-winning trainees showed that these awards were appreciated and encouraged motivation.
Conclusions Awards for excellence in paediatric is animportantway to appreciate staff that have made a significant positive impact on patient care and teamwork. While the junior doctors were the second most nominated group to receive awards, it is important to notice that they did not nominate any individuals in the last 12 months. One of the reasons might be that they were not aware of these awards and efforts will be made to include this in their future induction sessions. We feel that empowering trainees to nominate staff for these awards will help feel part of the team and receiving these awards will increase their morale. Learning from excellence (Greatix), an online positive feedback tool has recently been launched in our Trust and paediatric nominations will be monitored in the future.

\section{G140(P) GASTROSCHISIS: A 9 YEAR SINGLE CENTRE EXPERIENCE}

L Yee, C Douch, A Zaghal, S Chuang, S Habermann. Neonatal, Chelsea and Westminster Hospital, London, UK

\subsection{6/archdischild-2018-rcpch.136}

Aims To describe the outcomes of all babies with gastroschisis managed over a 9 year period at a single surgical unit.

Methods Retrospective study of all infants with gastroschisis, repaired between Jan 2007 to Jan 2016. They were analysed according to Simple vs Complex Gastroschisis and the Simple group subdivided into Primary vs Staged Closure.

Results We identified 56 babies. There were 45 simple and 10 complex cases. One baby was excluded with a closed gastroschisis. 26 babies with Simple Gastroschisis had primary and 19 had staged closure.

No deaths were noted. No significant differences in operative complications and unplanned re-operations were demonstrated. The median length of stay, time to full feeds and parenteral nutrition duration was not significantly different between simple and complex gastroschisis groups.

There was a significant difference in days to first feed and parenteral nutrition duration in Simple Gastroschisis managed with Primary closure and Staged closure (table 1).

\section{Abstract G140(P) Table 1}

\begin{tabular}{lllll}
\hline & Simple, staged & Simple, primary & Mean diff & P value \\
\hline Days to first feed & 9.5 & 18 & $8(3-17)$ & $<0.001$ \\
Days to full feed & 21 & 31 & $8(0-24)$ & 0.04 \\
Day of parenteral nutrition & 21 & 33 & $11(2-21)$ & 0.01 \\
\hline
\end{tabular}

\section{Conclusions}

1. Simple vs Complex Gastroschisis:

a. There was a higher but non significant risk of operative

complications in the complex group.

b. No statistically significant difference between the simple and complex groups. A sizable proportion of complex patients were excluded as they did not achieve outcome or were transferred to other units.

2. Primary vs Staged closure in Simple Gastroschisis:

a. No statistically significant difference in operative complications between primary and staged groups. 
b. Patients who underwent primary closure had significantly shorter times to first feed and a shorter durationof parenteral nutrition.

This study describes our practice and contributes to the growing pool of data regarding gastroschisis. In the absence of consensus, this may aid management decisions and reduce adverse outcomes.

\section{G141(P) TRANSFORMING CULTURE}

S Mohamed Cassim. Neonatal Unit, Aberdeen Maternity Hospital, NHS Grampian, Aberdeen, UK

\subsection{6/archdischild-2018-rcpch.137}

Background Trainee led initiative in response to National Training Survey (NTS) reflecting disengagement and disenchantment among trainees.

Aim To set up a Trainee Forum in a Neonatal Intensive Care Unit, which would be chaired by the senior trainees. The purpose was to identify trainee issues in a timely manner and highlight them to trainers, clinical director, deanery and the medical education team.

Methods A bi-monthly, closed meeting for trainees was established. Issues raised included improving teaching structure, postnatal ward set up, handover, valuing trainees and prioritising training needs. This was fed back by the senior trainee at the departmental Senior Staff Meeting. Working groups to target the different areas were established. Sessions with the 'Workplace Behaviour Champion' were organised to support and empower trainees. Trainee experience was measured at six months using PHEEM (Postgraduate Hospital Educational Environment Measure) and at twelve months on the NTS.

Results A joint medical/nursing education group was set up, resulting in revision of the teaching schedule and simulation. A 'What's on' bulletin of teaching opportunities was emailed out weekly. Teaching sessions were also highlighted at staff handovers. The handover structure was revised. A Quality Improvement(QI) project was established, reviewing ward rounds to maximise training opportunities. Positive behaviours were reinforced and mentoring was provided for trainees by senior trainees, management and the deanery. 'Baby-check' clinics were also set up as a QI project. The PHEEM questionnaire demonstrated improvement in some areas at six months, particularly in availability of training opportunities, education and morale. This was sustained on the NTS survey at 12 months.

Conclusions The Trainee Forum was successful in bringing all staff groups together as a team and motivating them to be the vehicles of change. This is an ongoing project with continuous feedback in real time from trainees. This multi-prong approach has demonstrated improvement in training on initial survey. Changing attitudes can be challenging but this process continues to engage trainees, consultants and managers towards modelling a positive work environment. It has also provided a platform for senior trainees to be involved in clinical leadership and engage with managers in a very meaningful way.

\section{Child Protection Special Interest Group}

\section{G142 FEMALE GENITAL MUTILATION SURVEILLANCE IN UNDER 16 YEARS OLDS IN THE UK AND IRELAND}

${ }^{1} \mathrm{~N}$ Ayadi O'Donnell, ${ }^{2} \mathrm{M}$ Leoni, ${ }^{3} \mathrm{G}$ Debelle, ${ }^{4} \mathrm{R}$ Lynn, ${ }^{5} \mathrm{~A}$ Armitage, ${ }^{5} \mathrm{SM}$ Creighton, ${ }^{6} \mathrm{R}$ Viner, ${ }^{5} \mathrm{D}$ Hodes. ${ }^{1}$ Department of Paediatrics, Whittington Hospital NHS Trust, London, UK; ${ }^{2}$ Research and Policy Division, Royal College of Paediatrics and Child Health, London, UK; ${ }^{3}$ Department of Paediatrics, Birmingham Women and Children's Hospital NHS Foundation Trust, Birmingham, UK; ${ }^{4}$ British Paediatric Surveillance Unit, Royal College of Paediatrics and Child Health, London, UKi ${ }^{5}$ Department of Paediatrics, University College London Hospitals NHS Foundation Trust, London, UK; ${ }^{6}$ Institute of Child Health, University College London, London, UK

\subsection{6/archdischild-2018-rcpch.138}

Aims Female genital mutilation (FGM) is the name given to procedures that involve partial or total removal or other injury to the female genitalia for nonmedical reasons. This study describes the presentation, incidence and clinical management of children with FGM in the UK and Republic of Ireland (ROI).

Methods Cases of FGM were reported using the established national British Paediatric Surveillance Unit (BPSU) reporting system. The data period is from November 2015-November 2017 with a 12 month follow up.

Results These interim results are from 120 cases reported (November 2015-September 2017). 61 (51\%) had confirmed FGM, 18 cases were reported in error or were duplicates, 36 questionnaires were incomplete [5 did not meet case definition]. $48 \%(n=29)$ of the 61 confirmed cases were classified as type 2.

In over $72 \%$ of the 61 cases, the parent disclosed child's history of FGM. At the time of diagnosis, $80 \%$ of children $(n=49)$ were four years or older (11 cases not recorded). Most children were diagnosed between 5 years and 10 years 11 months $(n=27)$ or 11 years and 15 years 11 months $(n=20)$ with 3 cases diagnosed between 0 and 4 years 11 months. In $51 \%$ of cases FGM was said to have been performed when the child was between 0 and 3 years $(n=31)$. $93 \%(n=57)$ were performed before arrival to the UK.

$13 \%(n=8)$ of children had medical symptoms attributed to FGM, with $7 \%(n=4)$ of children identified to have mental health symptoms relating to FGM. No children presented with a history of labiaplasty or genital piercing.

Conclusion Numbers reported were lower than expected for UK estimated prevalence with fewer physical and mental health symptoms than anticipated. Further information is needed to determine illegality under UK law. These findings should be used to educate health, social care, police and education on prevention programmes to help influence national policies.

\section{G143 HEAD TRAUMA IN UNDER 2'S - ACCIDENTAL VS INFLICTED?}

${ }^{1} \mathrm{G}$ Campbell, ${ }^{1} \mathrm{~S}$ McCallion, ${ }^{2} \mathrm{O}$ Kiuru, ${ }^{2} \mathrm{~S}$ Foster. ${ }^{1}$ Royal Hospital for Children, Glasgow, UK; ${ }^{2}$ Medical School, University of Glasgow, UK

10.1136/archdischild-2018-rcpch.139 